\title{
Multi-modular Current-Source Based Hybrid Converter for SMES
}

\author{
LiJun*, K.W.E. Cheng**, DeHong Xu*, D.Sutanto** \\ * Institute of Electrical Engineering, Zhejiang University, Hangzhou, 310027, P.R. China \\ ** Power Electronics Research Centre, Department of Electrical Engineering, \\ The Hong Kong Polytechnic University, Hong Kong SAR \\ http://perc.polyu.edu.hk
}

\begin{abstract}
A multi-modular current-source based hybrid converter mainly designed for superconducting magnetic energy storage system (SMES) is investigated in this paper. The converter consists of a four-module current source converter and one module of voltage source converter to reach high power rate and low harmonics. Circuit topology, control method and simulation results are given.
\end{abstract}

\section{INTRODUCTION}

Superconducting magnetic energy storage system (SMES) will be a perfect flexible ac transmission system (FACTS) component because of its high efficiency and rapid response to power demand [1],[2]. A bi-directional power converter called Power Condition System (PCS) is needed by SMES as a tie between the superconducting coil and the utility system. The PCS can be either a current source converter (CSC) or a voltage source converter (VSC) connected to a two-quadrant boost chopper. Since the superconducting coil is inherently a current source, the current source converter has more advantages to be a PCS for SMES than the voltage source converter [3], [4].

High power SMES system needs a converter with high power rating. Current source converters can be paralleled to directly constitute a multi-modular converter to meet the high power requirement. The switching frequency of the high power device is restricted to a relatively low switching rate. On the other hand, low contents of harmonics can be obtained in a multi-modular current source converter based on phasedshifted SPWM control [4],[5]. The more converter modules are used, the lower the harmonic frequency that can be produced, because the equivalent switching frequency is equal to the result of multiplying the real switching frequency by the number of converter modules used. In reference [4], an almost harmonic free $\mathrm{AC}$ current is obtained by employing 48 current source converter modules while the switching frequency is 2 on-off per cycle.

Though a multi-modular current source converter consisting of large number of modules gives us the advantages of low harmonics $\mathrm{AC}$ current and high total power rate, on the other hand, too many modules increase the cost, complicate constructing and maintenance of the system. On some occasion, we do not want to employ too many modules, but we still want to get low harmonics and high power. Then, a hybrid converter maybe a good approach.
One kind of hybrid converter is a voltage source converter, they usually use high power and low frequency switching device to control the most part of the total power demand and use relatively low power but much higher frequency device to control the remaining part of the power [6], [7], [8]. Thus low harmonics can be reached while the total switching loss can be kept small. They are called hybrid because they make use of different power switching devices.

Another kind of hybrid converter is a current source converter combined with a voltage source converter. The name of hybrid comes from the mixing of these tow different circuit topology. A hybrid converter composed of a squarewave mode current source converter and a high switching frequency voltage source converter has been introduced in [9]. Such converter basically is a current source type.

For information, the superconductors have also been used in transformer application for high frequency power conversion [10]. Certainly the use of superconductors in SMES is one of the typical applications. This paper introduces a multimodular current-source based hybrid converter which mainly aims to the application of the PCS of high power SMES system. The current source part consists of four current source converter modules controlled by low switching frequency phase-shifted SPWM. The voltage source part is a normal voltage source converter working on high switching frequency and current tracing control mode.

\section{TOPOLOGY OF THE HYBRID CONVERTER}

The main circuit of the proposed hybrid four-module current source converter is shown in Fig. 1. Each current converter module is a six-valves current source converter. The switching device is GTO (or IGCT) which has high power rating and low working frequency. The $\mathrm{AC}$ side of each module is connected together directly. The DC sides of converter modules are paralleled through DC inductors, then, these four converter modules are connected to the superconducting coil. The AC side of the voltage source converter is connected to the $\mathrm{AC}$ sides of the current source converter directly, the voltage source converter use IGBT, which allows it to work on a much higher switching frequency.

For a current source converter, the large output capacitor is indispensable for filtering and for the commutating of the switch, the resonance between the output capacitors and the inductor is a difficult problem, this filter can even amplify the 
low order harmonics. While adopting the topology in Fig.1, the large output capacitors are replaced by the DC capacitor of the voltage source converters (VSC). Only small value capacitors are needed for output filter, resonance in the output filter is avoided. Harmonic is low even a few current source modules are used. The power rating of the VSC is much smaller than the CSC and the total switching loss is still low. The voltage source converter looks like an embedded active power filter of the four-module current source converter.

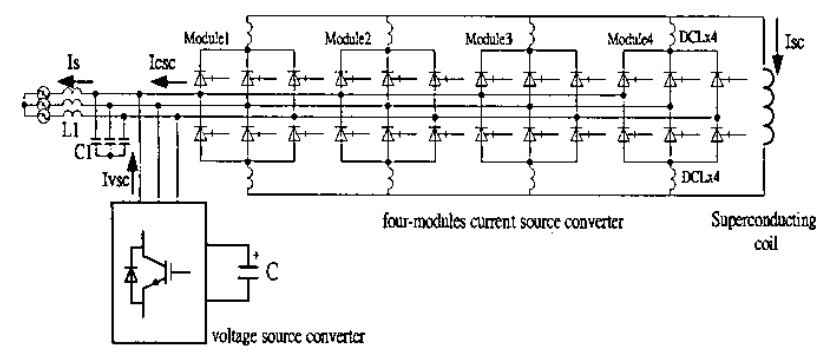

Fig. 1. Main circuit of the hybrid converter for SMES

\section{CONTROL OF THE CURRENT SOURCE CONVERTER}

\section{A. SPWM Control of the current source converter}

Phase-shifted SPWM control is applied to this four module current source converter to reduce harmonics while the switching frequency is low (can be as low as 150 or $300 \mathrm{~Hz}$ ). Fig. 2 gives the control logic diagram. The SPWM for current source converter need tri-logic signal [11]. The signals are produced as follows:

$$
\begin{aligned}
& X_{a}=\operatorname{sign}\left[v_{m a}(w t)-v_{c}\left(w_{s} t+\phi_{s}\right)\right] \\
& X_{b}=\operatorname{sign}\left[v_{m b}(w t)-v_{c}\left(w_{s} t+\phi_{s}\right)\right] \\
& X_{c}=\operatorname{sign}\left[v_{m c}(w t)-v_{c}\left(w_{s} t+\phi_{s}\right)\right] \\
& \operatorname{sign}(x)=\left[\begin{array}{c}
x \geq 0 \\
-1 \\
x<0
\end{array}\right] \\
& Y_{a}=\frac{1}{2}\left(X_{a}-X_{b}\right) \\
& Y_{b}=\frac{1}{2}\left(X_{b}-X_{c}\right) \\
& Y_{c}=\frac{1}{2}\left(X_{c}-X_{a}\right)
\end{aligned}
$$

As shown in Fig. 2 and Fig. 3, the modulation signals of each module are the same, the amplitude of the carrier of each module is equal, the phase angle of the carrier of each module is evenly shifted. In a four-module converter, at 3-times carrier frequency, the carrier phase angle difference between adjacent modules is:

$$
\left(360^{\circ} / 3\right) / 4=30^{\circ}
$$

Under such control method, the average DC current of each module differs from each other largely because of the different carrier angle when the frequency of carrier is low. Fig. 4 gives the DC current of each of the four modules. While the modulation index increased, the current unbalance between each module can be more serious. Such unbalance can make this direct paralleled multi-modular converter almost infeasible.

\section{B. Current balance control of the four-module converter}

A carrier-swapping method is applied to this phase-shifted SPWM controller to equalize the DC current-share of these four modules, as showing in Fig. 5. The phase-shifted triangle carriers of the four modules are swapped one time at every positive edge of the synchronous signal. For example, $\mathrm{Scl}^{\prime}$ (tri-angle carrier signal of module 1) is swapped as follows:

$$
\rightarrow \mathrm{Scl} \rightarrow \mathrm{Sc} 2 \rightarrow \mathrm{Sc} 3 \rightarrow \mathrm{Sc} 4 \rightarrow \mathrm{Sc} 1,
$$

Current unbalance caused by the carrier phase-shifting can then be eliminated. Fig. 6 shows the DC current of each module with carrier-swapping. The total AC current of the four modules before the output filter is shown in Fig. 7 .

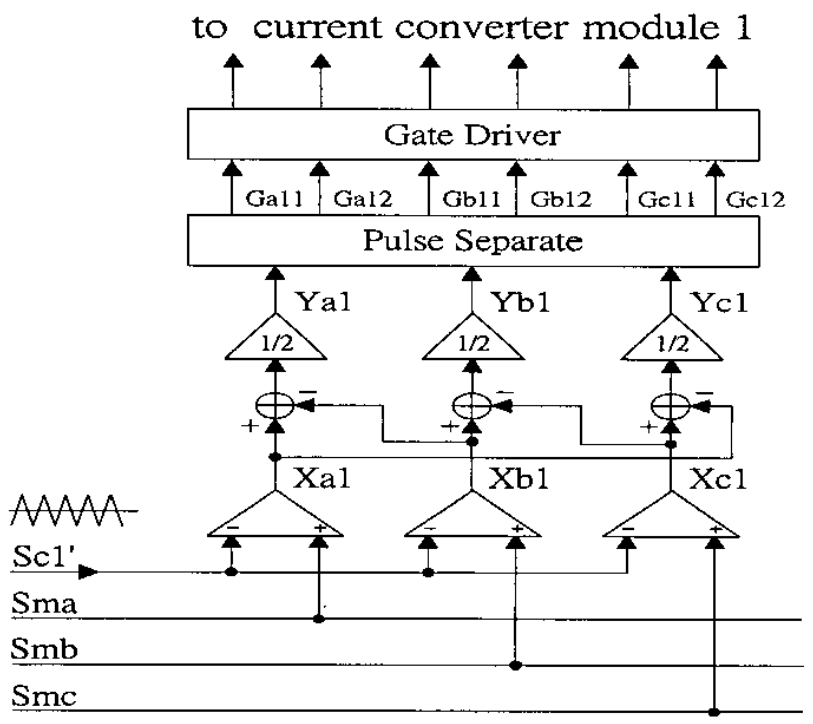

Fig. 2. Control logic of the current source converter modules

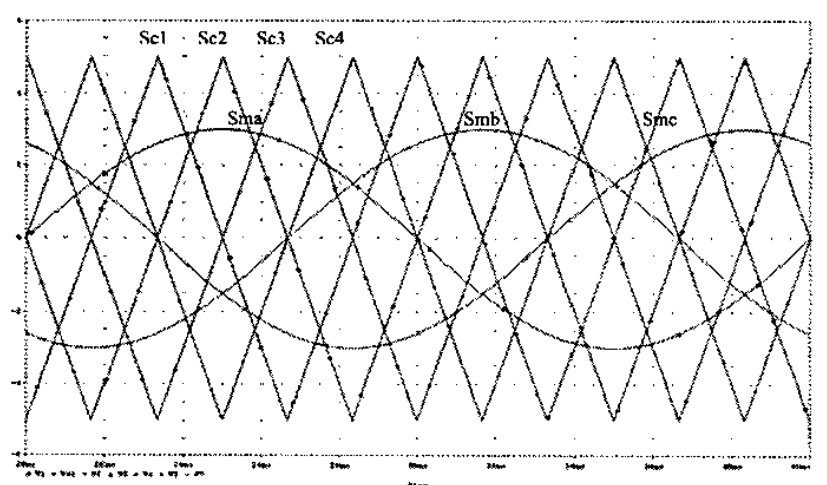

Fig. 3. Tri-angle carrier and modulation signal of each current module 


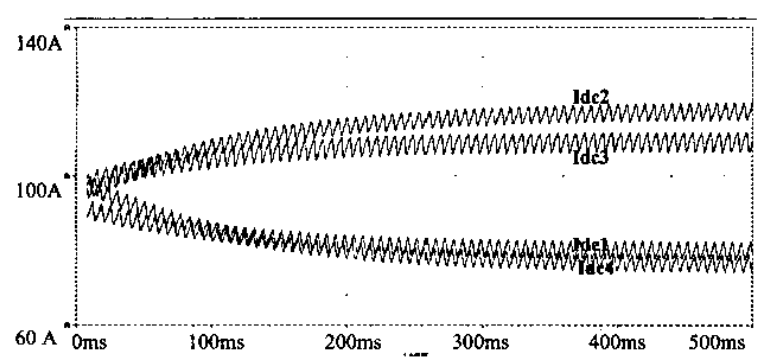

Fig. 4. Simulation waveform of DC current of each module with phase shifted SPWM without current balance control, $M=0.6, \alpha=30^{\circ}$.

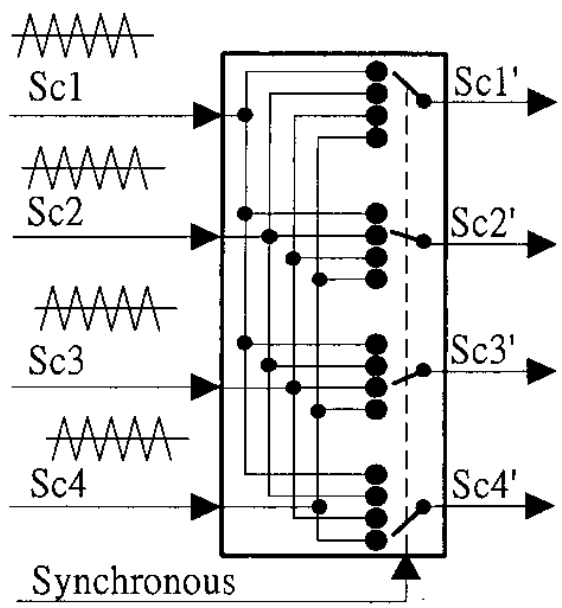

Fig. 5. Tri-angle carrier swapping logic

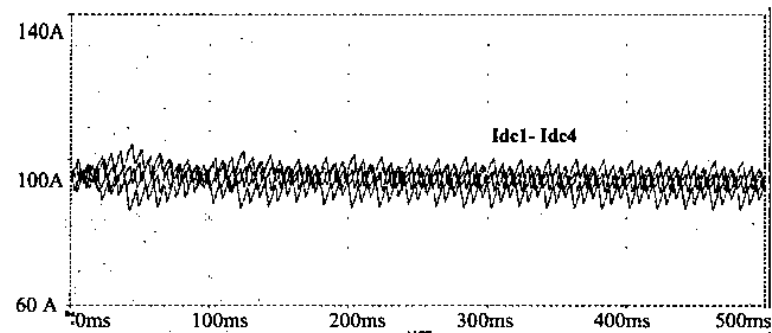

Fig. 6. Simulation waveform of DC current of each module, phase shifted SPWM with carrier- swapping, $M=0.6, \alpha=30^{\circ}$.

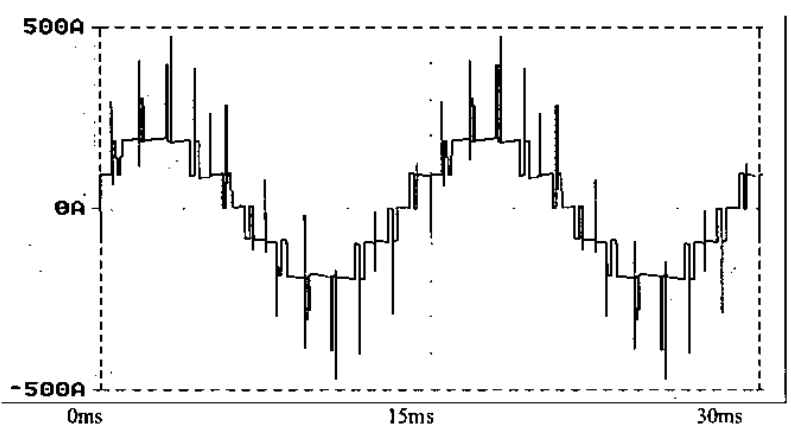

Fig. 7. Simulation waveform of total AC current of four modules

\section{Reduce the swapping period}

The carrier-swapping period is the same as the period of the synchronous signal, it equals to the period of the modulation signal. Considering the additional switching action needed by the swapping operation, this is the shortest period found while using carrier swapping to balance current sharing. At such period, the value of the DC inductors in each module should be about $100 \mathrm{mH}$. Too small value results in a larger ripple in the DC current of each module and serious distortion in the total AC current of the four modules. Smaller ripple in the $\mathrm{DC}$ current and less distorted total $\mathrm{AC}$ current can be obtained using larger DC inductors, but this method is not economical.

In Fig. 8, the carrier signal is not swapped, the DC current of each module is averaged by switching the DC inductors directly, each DC inductor is swapped between the four modules as follows:

$\rightarrow$ Module $1 \rightarrow$ Module $2 \rightarrow$ Module $3 \rightarrow$ Module $4 \rightarrow$ Module 1 ,

The swapping frequency can be very high, then the DC current ripple can be small even if the DC inductors are smail. But a lot of auxiliary switches are needed in this method, it is still not an economical and feasible way.

Since the main circuit of each module is completely the same, the difference is in the control signal. If we switch the control signal between the four modules, the effectiveness of current averaging is the same as switching the DC inductors. Fig. 9 shows the control logic of this method. The gate control signals of the upper three switches and the lower three switches in each module can be swapped separately (Fig. 8 and Fig. 9 only shows the upper side switch), then a higher swapping frequency can be used without increasing the additional switching operation required by the swapping operation. This is an improved method compared with the carrier swapping method. The disadvantage of this method is that it needs a more complex logic circuit to switch the control signal, but logic circuit is relatively cheap, and hence it is an insignificant disadvantage.

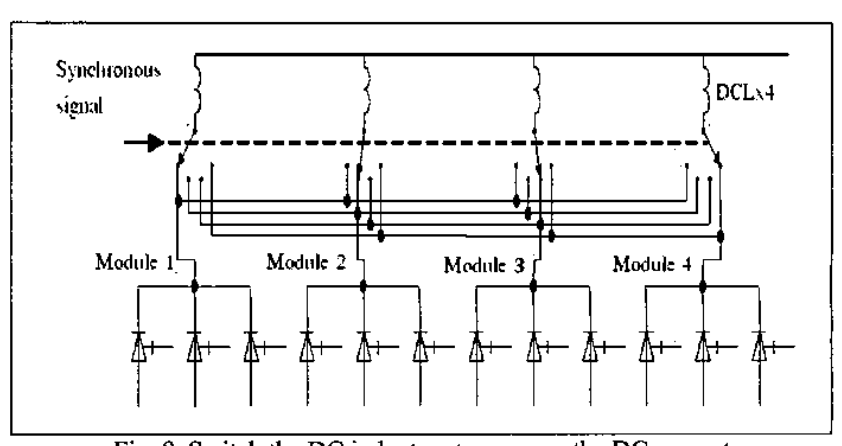

Fig. 8. Switch the DC inductors to average the DC current 


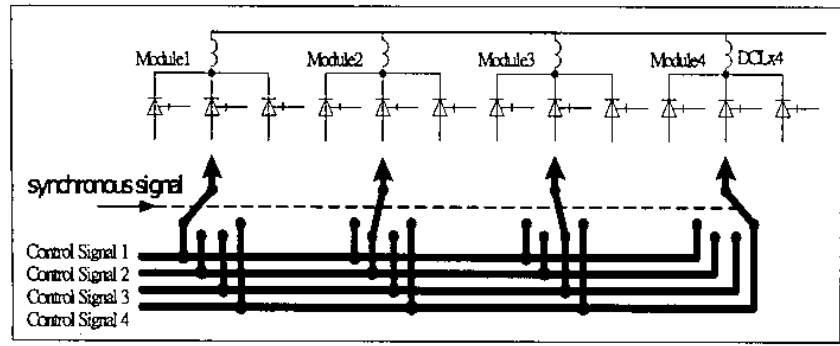

Fig. 9. Switch the gate control signal to average the DC current

\section{CONTROL OF THE VOlTAGE SOURCE CONVERTER}

By reducing the swapping period using the way mentioned above, the ripple of DC current can be kept low even when the DC inductor is small, the total AC current of the four modules can trace the control signal $\left(Y_{1}+Y_{2}+Y_{3}+Y_{4}\right)$ with less distortion, since the SPWM controlled converter is a linear amplifier [4].

The AC current of phase A of the four-module currentsource converter is :

\section{$I_{a}=\left(Y_{a 1}+Y_{a 2}+Y_{a 3}+Y_{a 4}\right) \cdot K$}

$K$ is the amplification coefficient of the four-module current converter:

$K=I_{s c} / 4$

$I_{s c}$ is the current of the super-conducting coil,

If the modulation signal of phase $\mathrm{A}$ is :

$S_{m a}=M \cdot \sin (\omega t)$

$M$ is the modulation index of SPWM

The fundamental part of $I_{a}$ is :

$I_{a l}=0.866 \cdot 4 \cdot M \cdot \sin \left(\omega t+30^{\circ}\right) \cdot K$

Thus, the harmonic part of the $I_{a}$ is as follow:

$I_{a h}=\left(\left(Y_{a I}+Y_{a 2}+Y_{a 3}+Y_{a 4}\right)-0.866 \cdot 4 \cdot M \cdot \sin \left(\omega t+30^{\circ}\right)\right) \cdot K$

The current signal, which the voltage source converter should trace, is:

$$
I_{v s c}=(-1) \cdot I_{a h}
$$

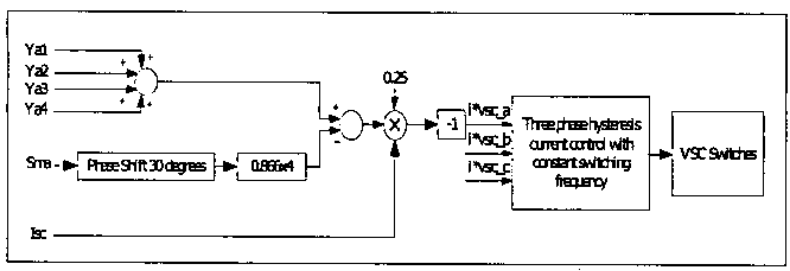

Fig. 10. Block diagram for phase A of the controller of the VSC

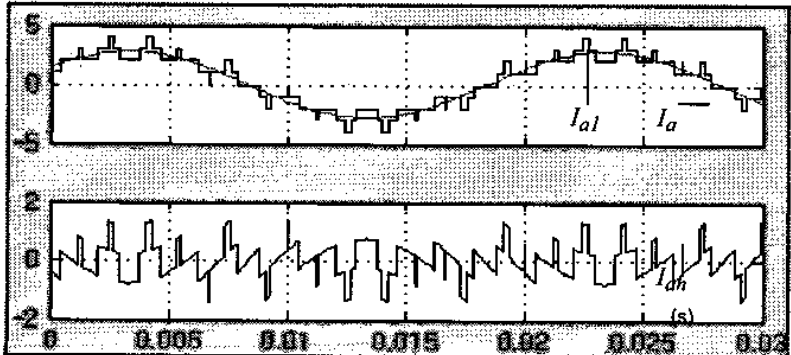

Fig. 11. The simulation waveform of total current of four-module converter $\left(I_{a}\right)$, its fundamental part $\left(I_{a l}\right)$ and its harmonic part $\left(I_{a h}\right)$
Fig. 10 gives the scheme for phase A of the VSC controller. The hysteresis control described in [12] is adopted in the simulation. The simulation waveforms of $I_{a}, I_{a l}$ and $I_{a h}$ are shown in Fig. 11.

Under such control, the voltage source converter absorbs the harmonics of the AC current of the four-module currentsource converter, the fundamental part of the total AC current of four modules is the injected into the utility power network. The voltage source converter acts as an active filter, the current error signal can be obtained easily because $I_{a}$ is foreknown. This is one of the advantages of this embedded active power filter compared with the common separate active power filter.

To obtain an AC source current $\left(I_{s}\right)$ with lowest harmonics, the AC current of the VSC $\left(I_{v s c}\right)$ should approach $I_{a h}$ as close as possible and the total $\mathrm{AC}$ current of the four-module CSC ( $\left.I_{c s c}\right)$ should approach $\left(Y_{a l}+Y_{a 2}+Y_{a 3}+Y_{a 4}\right) \cdot K$ as close as possible. By adopting proper current tracing control and using high-speed switches, the former requirement can be satisfied. To satisfy the latter one, the DC current unbalancing of the four-module CSC and the DC current ripple of each module should be reduced as more as possible, so, the current balance control and the way to reduce the swapping period mentioned in the former section is necessary.

\section{Simulation}

Fig. 12 shows the simulation waveform of $I_{c s c}, I_{v s c}$ and $I_{s}$. The voltage source converter is under hysteresis control to trace the harmonic current signal which is $(-1) \cdot I_{a h}$. The value of the output filter components is: $\mathrm{L}_{1}=150 \mu \mathrm{H}, \mathrm{C}_{1}=10 \mu \mathrm{F}$, the current of superconducting coil is $140 \mathrm{~A}$. We can see the current of AC source $\left(I_{s}\right)$ is nearly harmonic free even if the output capacity is very small. Fig. 13 gives the waveform of $I_{s}$ when the VSC is not connected to the four-module current source converter and the output capacity is $850 \mu \mathrm{F}$, a significant value of $7^{\text {th }}$ harmonic can be found in this condition even the equivalent switch frequency of this multimodular current source converter is $3 \times 4=12$.

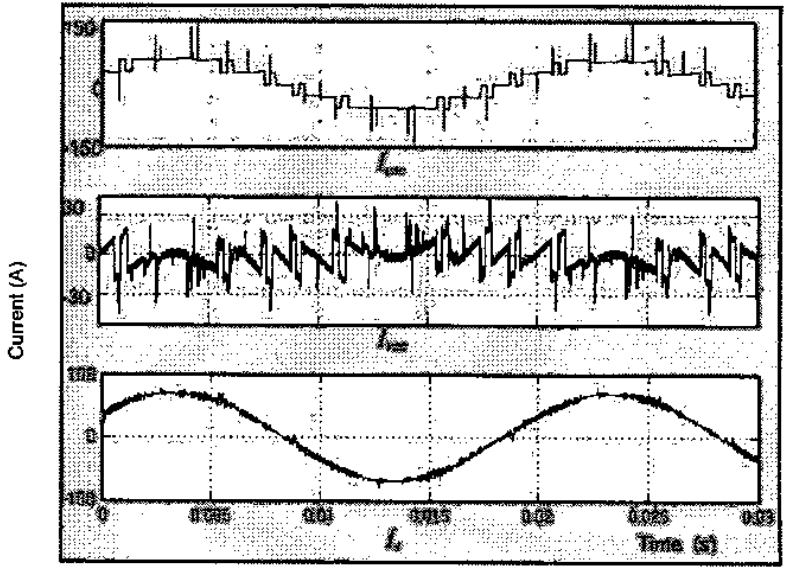

Fig. 12. The simulation waveform of the AC current of the four-module CSC $\left(I_{c s c}\right)$, VSC $\left(I_{v s c}\right)$ and the utility power source $\left(I_{s}\right)$. 


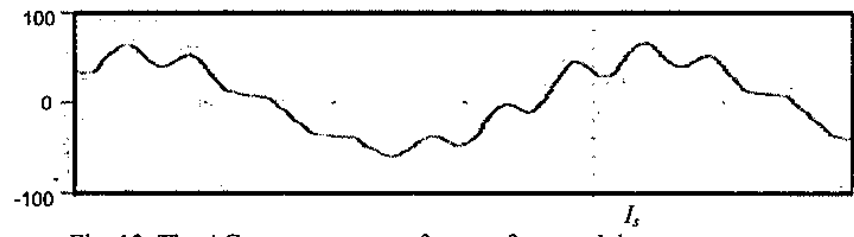

Fig. 13. The AC source current of a pure four-module current source converter (without the voltage source converter)

\section{CONCLUSION}

A multi-modular current-source based hybrid converter is investigated in this paper. The properties of the current source converter such as fast response and bi-directional power control can be kept and are very suitable for an SMES system. Because of the directly paralleled voltage source converter, the value of the output capacitors can be reduced to a much smaller value, the resonance in the output filter of the current source converter is avoided and the harmonics of the utility source current is kept low. The VSC in this hybrid converter is an embedded active power filter. Its control algorithm is simplified compared with the common separate active power filter because the current tracing signal is foreknown. The adoption of the four current modules not only improves the total power rating but also reduces the harmonics to a known value while phase-shifted SPWM control is employed, thus the power rating of the VSC can be reduced to a much smaller value compared with the CSC. In many applications, parallel operation is preferred because it offered some degree of fault tolerance as compared to other single module system. The SPWM control of the multi-modular current converter also gives us more flexibility of the control of SMES when compared with the square wave control mode.

\section{ACKNOWLEDGEMENT}

The authors thank the financial support of the Research Committee of Hong Kong Polytechnic University for the project G-T177

\section{REFERENCE}

[1] C.S. Hsu and W.J. Lee, "Superconducting magnetic energy storage for power system applications" IEEE Trans. on Industry Applications, Volume: 29 Issue: 5 , Sept.-Oct. 1993 pp. $990-996$

[2] V. Karasik, K. Dixon, C. Weber, B. Batchelder, G. Campbell and P. Ribeiro, "SMES for power utility applications: a review of technical and cost considerations" IEEE Trans. on Applied Superconductivity, Volume: 9 Issue: 2 Part: 1, June 1999 pp. $541-546$

[3] I.J. Iglesias, J. Acero and A. Bautista, "Comparative study and simulation of optimal converter topologies for SMES systems" IEEE Trans. on Applied Superconductivity, Volume: 5 Issue: 2 Part: 1 , June 1995 pp. 254 -257

[4] Z.C. Zhang and B.T. Ooi, "Multimodular current-source SPWM converters for a superconducting magnetic energy storage system" IEEE Trans. on Power Electronics, Volume: 8 Issue: 3 , July 1993 pp. $250-256$

[5] K. Imaie, O. Tsukamoto and Y. Nagai, "Control strategies for multiplc parallel current-source converters of SMES system" IEEE Trans. on Power Electronics, Volume: 15 Issue: 2, March 2000 pp. 377-385

[6] M. D. Manjrekar, P. K. Steimer and T. A. Lipo, "Hybrid multilevel power conversion system: a competitive solution for high-power applications " IEEE Trans. on Industry Applications, Volume: 36 Issue: 3, May-June 2000 pp. $834-841$

[7] S. Fukuda, Y. Kubo and M. Kitano, "Introduction of a hybrid multiconverter system and its control strategy "Proceedings of the Power Conversion Conference, 2002. PCC-Osaka 2002, Vol: 2, 2002 pp. $372-377$

[8] T. Gopalarathnam, M. D. Manjrekar and P. K. Steimer, "Investigations on a unified controller for a practical hybrid multilevel power converter" Seventeenth Annual IEEE Applied Power Electronics Conference and Exposition, 2002. APEC 2002, Volume: 2, 2002 pp. $1024-1030$

[9] A. M. Trzynadlowski, N. Patriciu, F. Blaabjerg and J.K. Pedersen, "A hybrid, current-source/voltage-source power inverter circuit "IEEE Trans. on Power Electronics, Volume: 16 Issue: 6, Nov. 2001 pp. 866-871

[10] Chan, H.L.; Cheng, K.W.E.; Sutanto, D., "Superconducting selfresonant air-core transformer", Power Electronics Specialists Conference, 2000., Vol: 1 , pp.314 -319.

[11] X. Wang and B. T. Ooi, "Unity PF current-source rectifier based on dynamic trilogic PWM" IEEE Trans. on Power Electronics, Volume: 8 Issue: 3, July 1993 pp. $288-294$

[12] Q. Yao and D. G. Holmes, "A simple, novel method for variablehysteresis-band current control of a threc phase inverter with constant switching frequency" 1993 IEEE Industry Applications Society Annual Meeting, 2-8 Oct 1993 Vol: 2 , pp. $1122-1129$

[12] Chan, H.L.; Cheng, K.W.E.; Sutanto, D., "Superconducting selfresonant air-core transformer", Power Electronics Specialists Conference, 2000, Vol: 1 , pp.314 -319. 